\title{
Finite complements trigger reality responses in attitude verb acquisition... but so do non-finite complements
}

\author{
Kaitlyn Harrigan*
}

\begin{abstract}
The syntactic bootstrapping hypothesis was developed to explain how children learn verbs whose meanings are opaque, e.g. attitude verbs, which refer to the mental state of the subject of the sentence. Belief verbs (like think) take finite complements, while desire verbs (like want) take non-finite complements. Children differentiate these subclasses by three: they are lured by reality when there is a mismatch between the subject's belief and reality when interpreting think, but not with want. Previous work also shows that when interpreting a less common attitude verb, hope, children are influenced by syntactic frame, supporting view that syntax guides children's acquisition of attitude verbs. The current study investigates when syntax becomes useful to the learner. Children are presented with sentences including a novel verb with either a finite or a non-finite complement. Children are not influenced by syntax when interpreting a novel attitude verb, suggesting that syntactic complements only become useful for hypothesizing meaning once the learner has some experience with a specific attitude verb.
\end{abstract}

Keywords. language acquisition; word learning; verb learning; syntactic bootstrapping; attitude verbs

1. Introduction. Word learning is a massively challenging task for the human language learner. Words refer to concepts, not individual objects, but children are never exposed directly to concepts. How can the child ever correctly learn to categorize new furry four-legged animals as either $\operatorname{dogs}$ or not-dogs? The difficulty escalates when we consider words with no obvious physical correlates. One such class is attitude verbs, such as think and want, which refer to the mental state of the subject of the sentence (1)-(2).

(1) Felix thinks that it's raining.

(2) Felix wants it to rain.

The syntactic bootstrapping hypothesis was developed for exactly such cases - words whose meanings are closed to observation. Syntactic bootstrapping predicts that children use syntactic distribution to hypothesize semantic properties, the syntax acting as a sort of "zoom lens" to word meaning (Gleitman 1990). Previous work on syntactic bootstrapping has confirmed that children are sensitive to syntactic distribution, and that they do, in fact, use this information to hypothesize word meaning, although bootstrapping work has primarily focused on transitivity (Fisher et al. 1991, Fisher et al. 2009, Gleitman 1990, Naigles 1990, Yuan \& Fisher 2009, a.o.). Attitude verbs are a class of words for which linguistic cues might be particularly valuable, or even necessary, given that one cannot directly observe events of thinking or wanting. Harrigan, Hacquard \& Lidz (2019) investigate syntactic bootstrapping for attitude verbs, and find evidence that children are sensitive to syntactic structure when interpreting a lesser-known attitude verb, hope. These findings support the original goal of the syntactic bootstrapping hypothesis, but more work is still

\footnotetext{
* I am grateful to many people who contributed to this work, including: undergraduate research assistants Valerie Bambha, Colin Wilson, Rebecca Smyder, Grace Marks, Mackenzie Phalan, and Abby Fergus. Deb Harrigan for experimental materials; and members of the Child Language Lab and the Computational and Experimental Linguistics Lab at William \& Mary for input on earlier versions of this work. Author: Kaitlyn Harrigan, William \& Mary (kharrigan@wm.edu).
} 
needed to fully understand the role that syntax plays in acquiring attitude verbs. This paper explores the boundaries of syntactic bootstrapping for attitude verbs, expanding on the findings from Harrigan et al. (2019), testing the role of syntax in interpreting a truly novel attitude verb. The findings of the current study suggest that although syntax is a valuable cue for the learner about attitude verb meaning, it may not be available to the learner at every point in development. In order for syntactic bootstrapping to be a viable learning strategy, it must both be true that semantic properties are predictable from syntactic distribution, and that children are sensitive to this connection at the relevant point in development. The following two sections will address each of these points.

1.1. Syntactic AND SEMANTIC PROPERTIES OF ATtitUde VERBS. Attitude verbs have been argued to fall into two main semantic classes: Bolinger's 'representationals', which express judgments of truth, such as think or say, and 'preferentials', which express preferences, such as want or wish (Bolinger 1968; Searle \& Vanderveken 1985; Villalta 2000; 2008; Anand \& Hacquard 2013, a.o.). This split in semantic subclass has also argued to be tracked by syntactic distribution. In English, this manifests in finiteness in the complement-representationals (like think) take finite complements (1), while preferentials (like want) take non-finite complements (2).

While finiteness represents the relevant syntactic property in English, other language may track this split syntactically. In Romance languages, for example, representationals take complements marked with indicative mood, while preferentials take complements marked with the subjunctive mood (Bolinger 1968, Hooper 1975, Farkas 1985 Giannakidou 1997, Villalta 2008, Anand \& Hac-quard 2013, a.o.). Although the specific features associated with both semantic classes differ cross-linguistically, they have been argued to converge at an abstract level (see Hacquard \& Lidz 2018 for a full discussion): the complements of representationals allow syntactic features found in declarative main clauses in that language, the complements of preferentials do not. Sensitivity to main clause syntax in embedded clauses may serve as a useful cue to the learner about semantic subclass. In this way, linguistic theory supports the possibility of syntactic bootstrapping as a fruitful learning strategy for attitude verbs.

1.2. Bootstrapping FOR ATtitUde Verbs. Given the abstractness of the concepts to which they refer, and the difficulty Attitude verbs are, in fact, acquired later than many other types of verbs, however not all verbs of this class are acquired equally late. Previous research on attitude verb acquisition focuses on the two most common attitude verbs in child-directed speech: think and want. Many studies show an asymmetry in the acquisition of think and want until at least age four (de Villiers \& de Villiers 2009, de Villiers \& Pyers 2002, Papafragou et al 2007, Perner et al 2003, Wellman et al. 2001, a.o.). Specifically, when acquiring belief verbs, children make a classic "false belief" error - they are lured by reality when there is a mismatch between the subject's belief and reality. This same reality error is not observed in the acquisition of other mental state verbs, such as want (Harrigan et al 2019, Rakoczy et al. 2007).

The observations that think and want have different syntactic distributions and that children are differentiating these verbs early on serve as a starting point for hypothesizing that syntax may play a role in children's early hypotheses about attitude verb acquisition. However, both want and think occur quite frequently in child-directed input (Harrigan 2015, Harrigan et al. 2019, Wellman \& Wooley 1990). Given that it is not clear what other information might be co-occurring in the child's environment, more evidence is needed to determine the role of syntax in driving this categorization. Harrigan et al. (2019) seek to better understand the contribution of syntax in acquiring attitude verbs. In a novel methodology, they demonstrate children's sensitivity to syntax in interpreting an unknown attitude verb, hope. The "game task" in Harrigan et al. sets up a context that supports and 
makes salient three types of interpretations: belief, desire, and reality responses. In their task, the child helps pull shapes out of a box and show them to a puppet, Froggy, who has both a desireabout the shape on every trial. Selection of certain shapes results in Froggy getting a sticker, inducing a desire about which shape will be selected on every trial; before each shape's identity is revealed, Froggy is shown a clue about the shape, resulting in a belief about the shape on every trial. Thus, on any trial, children might respond based on Froggy's desire about the selected shape, his belief about the shape's identity, or be lured by the reality of the shape's identity.

Harrigan et al. argue that hope is an ideal initial test case for syntactic bootstrapping for attitude verbs. It has unique syntactic and semantic properties, placing it in both the desire and belief subclasses described in the previous section. While the meaning primarily reports the desires of the subject of the sentence, hope requires that the complement is consistent with the beliefs of the subject of the sentence (Portner 1992, see (3)-(4)).

(3) Mom knows that Felix is playing outside, but she wants him to be in bed.

(4) ?Mom knows that Felix is playing outside, but she hopes he's in bed.

These semantic properties are reflected in the syntax: hope can occur with both a finite complement (5), like think; or with a non-finite complement (6) like want.

(5) Froggy hopes the shape is a heart.

(6) Froggy hopes to get a heart.

In the game task setup, Harrigan et al. manipulate the syntactic frame in which hope occurs. A puppet "watches" the game and utters the test sentences (5)-(6) on each trial before the shape's identity is revealed to Froggy. The neutral context of the game supports interpretations based on belief, desire or reality, and the manipulation of the syntactic frame for hope They find that when children hear hope with a finite complement (5), they are lured by reality, responding based on the shape's identity, and not on Froggy's beliefs (based on color) or his desires (based on his established preferences), showing the classic "false belief error". Interpretation of hope with a finite complement patterns with children's performance with think in previous studies, and with their performance on think in the same game task. They conclude that children are using the finite complement to hypothesize the meaning of representational attitude verbs. When children hear hope with a non-finite complement (6), they are able to override reality, and respond based on Froggy's desires. This performance patterns with previous studies' findings reporting success with want sentences, as well as patterning with children's performance on want in the same game task. Harrigan et al. conclude that children are using the non-finite complement to hypothesize the meaning of preferential attitude verbs.

While the studies reported in Harrigan et al. 2019 provide a starting point for understanding how syntactic complement contributes to children's acquisition of attitude verbs, several questions remain. That children are influenced by syntactic frame when interpreting hope suggests that children's semantic representation for hope is not yet cemented. Yet, it is not a completely novel verb, either, as it does appear with some regularity in child-directed input. This leaves open questions about when syntax becomes useful to the learner. Is it useful immediately? Or does the child need some exposure to a verb before being able to utilize syntactic information for attitude verb subclass categorization? Building on Harrigan et al. 2019, the current study presents children with sentences with a truly novel verb, kertunks, using either a finite or a nonfinite complement (7)-(8).

(7) Froggy kertunks the shape is a heart.

(8) Froggy kertunks to get a heart. 
Using a novel verb controls for the possible role of experience with hope. The current study finds that, unlike with hope, children are lured by reality with both a finite and a non-finite complement, suggesting that although syntax is useful to the learner in acquiring attitude verbs, syntactic complement is not equally useful to the learner at every stage of development.

2. Experiment. This study builds on the work reported in Harrigan et al. 2019, investigating children's sensitivity to syntactic structure in interpreting novel attitude verbs. In this study, children hear sentences with a novel attitude verb, kertunks, with both finite (7) and non-finite (8) complements.

2.1. SubJECTS. Participants were 24 children aged $4 ; 0$ to $5 ; 3$ (mean=4;6). Three additional children were excluded due to getting too many controls incorrect. To be included, children needed to complete the experiment and get both controls correct. Children were recruited from Williamsburg, VA area, and tested either at their local preschools, or in the Child Language Lab at William \& Mary.

2.2. Design AND MATERIAls. The current study is a game task based on the procedure reported in Harrigan et al. 2019. This game makes salient both the beliefs and desires of a character. This allows syntactic frame to be manipulated between subjects. The child plays with a puppet, Dragon. The child and one experimenter are behind an occluder, while Dragon is on the other side. In front of the child is a box with 40 colored hearts and stars. Color is predictive of shape: 15 hearts are red and 5 are yellow, and 15 stars are yellow and 5 are red. In the game, the experimenter pulls shapes out of the box to show Dragon. When the shape is a heart, the child gives Dragon a sticker; therefore his desire on every trial is for a heart. On each trial, before Dragon sees what the shape is, he sees a 'clue,' which is ambiguous in shape. There is an opening in the occluder through which Dragon is shown a point - either the point of the heart or one of the points of the star (Figure 1).

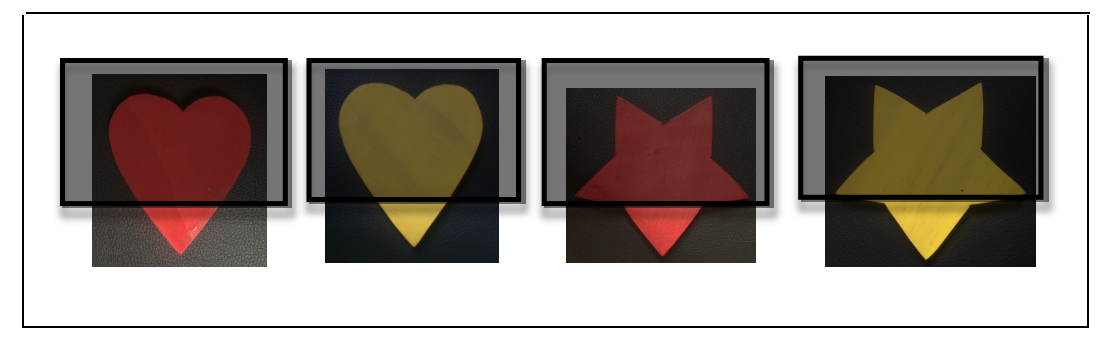

Figure 1. All four shapes and the "point" which is revealed to the puppet during the clue phase.

On every trial, Dragon has both a desire about the shape-because he always wants the shape to be a heart, and a belief - because whenever it is red, he thinks it's a heart and when it's yellow he thinks it's a star. This set-up allows another puppet, Professor Goobligook, whom the child is told is 'very smart, but not very good at games, and needs help to learn how to play this game,' to utter test sentences either about what Dragon kertunks using either the finite (9)-(10) or nonfinite (11)-(12) frame. The child's job in the task is then to say whether Professor Goobligook is correct or incorrect. 

Dragon kertunks that the shape is a heart. Dragon kertunks that the shape is a star. Dragon kertunks to get a heart. Dragon kertunks to get a star.

In a $2 \times 4 \times 2$ design, FRAME was manipulated as a between-subjects factor (kertunks-that $(\mathrm{n}=12)$, kertunks-to $(\mathrm{n}=12))$, CONDITION (red heart, red star, yellow heart, yellow star) and MENTIONED shape (heart vs. star) as within-subjects factors. The child's response of yes or no was the dependent measure. On every trial, Dragon had both a belief and a desire about the next shape. His 'belief' was dictated by the color of the clue. When color correctly predicted shape (red heart, yellow star conditions), his belief was true. When it did not (red star, yellow heart), his belief was false. Similarly, his desire for a heart was sometimes fulfilled (heart conditions), and sometimes unfulfilled (star conditions). The silly puppet Professor Goobliogook uttered test sentences. This set-up allows for an ideal comparison of interpretation across syntactic frame, as interpretations based on belief, desire, and reality are all possible in the experimental context. The experiment includes 6 of each star item (red star, yellow star), and two of each heart item (red heart, yellow heart), for a total of 16 test items per child. Table 1 shows all 16 conditions.

\begin{tabular}{|c|c|c|}
\hline $\begin{array}{c}\text { FRAME } \\
\text { (between subjects) }\end{array}$ & $\begin{array}{c}\text { CONDITION } \\
\text { (within subjects) }\end{array}$ & $\begin{array}{c}\text { MENTIONED } \\
\text { (within subjects) }\end{array}$ \\
\hline \multirow{8}{*}{ Kertunks-that } & \multirow{2}{*}{ Red Heart } & Heart \\
\hline & & Star \\
\hline & \multirow[t]{2}{*}{ Red Star } & Heart \\
\hline & & Star \\
\hline & \multirow[t]{2}{*}{ Yellow Heart } & Heart \\
\hline & & Star \\
\hline & \multirow[t]{2}{*}{ Yellow Star } & Heart \\
\hline & & Star \\
\hline \multirow[t]{8}{*}{ Kertunks-to } & \multirow[t]{2}{*}{ Red Heart } & Heart \\
\hline & & Star \\
\hline & \multirow[t]{2}{*}{ Red Star } & Heart \\
\hline & & Star \\
\hline & \multirow[t]{2}{*}{ Yellow Heart } & Heart \\
\hline & & Star \\
\hline & \multirow[t]{2}{*}{ Yellow Star } & Heart \\
\hline & & Star \\
\hline
\end{tabular}

Table 1. Between- and within-subjects conditions.

2.3. Procedure. Each child was tested in a quiet room with two experimenters. One experimenter sat next to the child and gave the instructions about the game. This experimenter controlled the silly puppet, 'Professor Goobligook,' and delivered the test sentences. The second experimenter sat on the other side of the occluder, and played Dragon (Figure 2). 


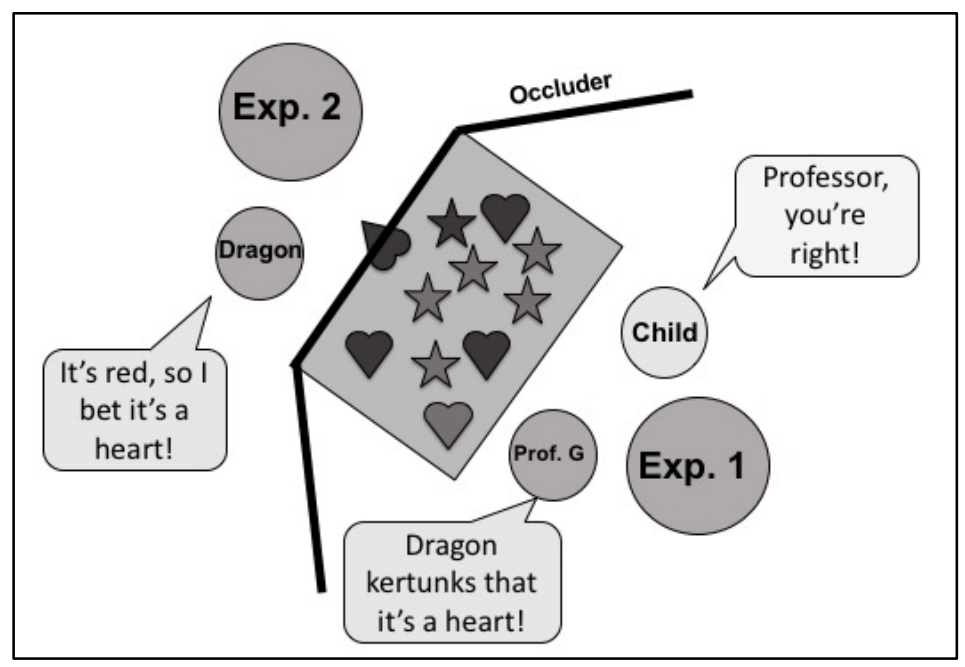

Figure 2. Experimental set-up.

The second experimenter also coded the child's responses. Permission was obtained from parents to video record each subject in case any responses were missed during the initial coding. The child completed several practice sessions to ensure that they understood all the necessary elements of the game, including Dragon's desires and beliefs in this context (see Harrigan et al. 2019 for more thorough description of practice session procedures).

2.4. EstABLishing DESIRES. The child was told that Dragon 'loves getting hearts, but doesn't like getting stars at all' because every time we pull out a heart, Dragon gets a sticker. The child was encouraged to 'help' the experimenter by being in charge of giving Dragon stickers every time we pull out a heart. This compels the child to keep track of what shapes we are pulling out, as well as motivating Dragon's preferences about shape. Before the test sentences began, the experimenter practiced pulling out shapes with the child, and let the child practice giving Dragon a sticker on the relevant trials. This allowed the child to solidify their understanding of the game and of Dragon's desires. It also allowed the experimenter to check that the child understood the game and Dragon's desires. Children were very good at remembering when they should give Dragon a sticker, and they enjoyed giving the stickers and watching Dragon's reactions to getting both kinds of shapes.

2.5. Establishing BeliEFs. It is also critical that Dragon's beliefs are established before the test sentences begin. Motivations for beliefs are based on color-that when the clue is red, Dragon thinks it's a heart and when it's yellow, he thinks it's a star. During the set-up, the child was shown clues and got to guess the shape's identity. This allowed them to experience having a false belief - sometimes they guess heart but it's actually a star. On each of these practice trials, Dragon also got to make a guess. He looked at the clue, and speculated about the shape's identity based on the color, saying 'hmm, this time it's red, so it's probably a heart!'. This established Dragon's beliefs and their motivations. The experimenter then confirmed that the child had learned this connection by asking about Dragon's guesses based on color-'when Dragon sees a red clue, what kind of shape does he guess?'.

2.6. InTRODUCING "ProfESSOR GOOBLIGOOK". Before the test trials began, children were also introduced to the silly puppet, Professor Goobligook, who watched them play the game with Dragon. In order to motivate Professor Goobligook's use of the novel verb in the test phase, children were told that he is 'very smart and uses a lot of big words, but is also pretty forgetful 
and not very good at playing games.' Professor Goobligook introduced himself, using several low frequency lexical items that the child is not likely to know:

Oh, well hello there, youngster! What a very appealing and rapturous day it is today! And look at all of this! Simply splendid! I see that we have a delightful architecture here for playing this daunting and vigorous game! And we have some exuberant players-ready to go! ... Might I join you in your endeavor?

Children responded very well to both Professor Goobligook's introduction, as well as his use of the novel verb during the test phase.

2.7. TEST SENTENCES. During the test phase, the box of shapes and the occluder were turned so that the child could see which shape was under discussion. They were told that now they were going to be able to 'peek' while we showed Dragon some clues, and Professor Goobligook was going to say something about 'what Dragon likes, or what he might guess.' Then the experimenter began showing Dragon clues, and uttering test sentences. For each trial, the experimenter chose which shape to show Dragon (often letting the child 'help' decide), and then the experimenter slid the shape into the slot so Dragon could see the clue on the other side. After Dragon saw the clue, Professor Goobligook uttered the test sentence, and the child told him whether he was right or wrong. After the child responded to the test utterance, the experimenter showed Dragon the shape, and he responded appropriately. If it was a heart, the child gave him a sticker. Children tended to be interested and engaged throughout the entire process, which took about 20 minutes.

RESULTS. Children's responses were coded as the child delivered the response by the second experimenter. There are three possible response patterns given the experimental setup - belief, desire, and reality. Harrigan et al. found two of these three patterns observed in interpretation of hope. When children heard hope with a finite complement, they gave reality responses; when they heard hope with a non-finite complement, they gave reality responses. Based on this, children were predicted to give one of these two responses types when interpreting sentences with kertunks. If children interpret sentence as describing Dragon's desires, they should assent to sentences that mention 'heart' (13)/(15), regardless of what shape and color the shape actually is, because Dragon always wants it to be a heart (Table 2, 'desire responses' column). If children give responses based on reality, they should assent to sentences in which mentioned shape and actual shape are the same, regardless of color, desire or belief (table 2, 'reality responses' column). Children's responses were measured in percent yes responses. Red heart items were counted as controls: because this is a case where desire (and belief) align with reality, we predict the same pattern of responses regardless of whether participants are responding based on desire or reality. They should say yes when a heart is mentioned (13)/(15) and no when a star is mentioned (14)/(16), regardless of frame. We excluded 3 participants who did not get both red heart items correct.

(13) Dragony kertunks that the shape is a heart.

(14) Dragon kertunks that the shape is a star.

(15) Dragon kertunks to get a heart.

(16) Dragon kertunks to get a star. 


\begin{tabular}{|c|c|c|c|c|}
\hline $\begin{array}{c}\text { FRAME } \\
\text { (between subjects) }\end{array}$ & $\begin{array}{c}\text { CONDITION } \\
\text { (within subjects) }\end{array}$ & MENTiOned & $\begin{array}{c}\text { Desire } \\
\text { responses }\end{array}$ & $\begin{array}{l}\text { Reality } \\
\text { responses }\end{array}$ \\
\hline \multirow[t]{8}{*}{ Kertunks-that } & \multirow[t]{2}{*}{ Red Heart } & Heart & Yes & Yes \\
\hline & & Star & No & No \\
\hline & \multirow[t]{2}{*}{ Red Star } & Heart & Yes & No \\
\hline & & Star & No & Yes \\
\hline & \multirow[t]{2}{*}{ Yellow Heart } & Heart & Yes & Yes \\
\hline & & Star & No & No \\
\hline & \multirow[t]{2}{*}{ Yellow Star } & Heart & Yes & No \\
\hline & & Star & No & Yes \\
\hline \multirow[t]{8}{*}{ Kertunks-to } & \multirow[t]{2}{*}{ Red Heart } & Heart & Yes & Yes \\
\hline & & Star & No & No \\
\hline & \multirow[t]{2}{*}{ Red Star } & Heart & Yes & No \\
\hline & & Star & No & Yes \\
\hline & \multirow[t]{2}{*}{ Yellow Heart } & Heart & Yes & Yes \\
\hline & & Star & No & No \\
\hline & \multirow[t]{2}{*}{ Yellow Star } & Heart & Yes & No \\
\hline & & Star & No & Yes \\
\hline
\end{tabular}

Table 2. Predictions for desire and reality responses.

The reality responses from Harrigan et al. in the finite condition are replicated here: when children hear the novel verb with a finite complement, they respond based on reality-they assent to sentences only when the mentioned shape matched the actual shape. Children are also lured by reality, however, when they hear the novel verb with a non-finite complement. Although the reality response is not as strong for the non-finite condition, they are still more likely to assent to sentences in which mentioned shape and actual shape matched. This is particularly evident in the star conditions - in this case, reality (star) differs from Dragon's desire (heart), and children are always more likely to give responses consistent with reality and not Dragon's desire. Proportion yes responses for all conditions are shown in Table 3 and Figure 3. 


\begin{tabular}{|c|c|c|c|c|c|}
\hline $\begin{array}{c}\text { FRAME } \\
\text { (between subjects) }\end{array}$ & $\begin{array}{c}\text { CONDITION } \\
\text { (within subjects) }\end{array}$ & MENTIONED & $\begin{array}{c}\text { Desire } \\
\text { responses }\end{array}$ & $\begin{array}{l}\text { Reality } \\
\text { responses }\end{array}$ & $\begin{array}{c}\text { Proportion } \\
\text { yes responses } \\
(\mathrm{SD})\end{array}$ \\
\hline \multirow[t]{8}{*}{ Kertunks-that } & \multirow[t]{2}{*}{ Red Heart } & Heart & Yes & Yes & $1.00(0)$ \\
\hline & & Star & No & No & $.00(0)$ \\
\hline & \multirow[t]{2}{*}{ Red Star } & Heart & Yes & No & $.13(.35)$ \\
\hline & & Star & No & Yes & $.75(.44)$ \\
\hline & \multirow[t]{2}{*}{ Yellow Heart } & Heart & Yes & Yes & $1.00(0)$ \\
\hline & & Star & No & No & $.10(.32)$ \\
\hline & \multirow[t]{2}{*}{ Yellow Star } & Heart & Yes & No & $.20 .41)$ \\
\hline & & Star & No & Yes & $.64(.49)$ \\
\hline \multirow[t]{8}{*}{ Kertunks-to } & \multirow[t]{2}{*}{ Red Heart } & Heart & Yes & Yes & $1.00(0)$ \\
\hline & & Star & No & No & $.15(.38)$ \\
\hline & \multirow[t]{2}{*}{ Red Star } & Heart & Yes & No & $.26(.44)$ \\
\hline & & Star & No & Yes & $.45(.50)$ \\
\hline & \multirow[t]{2}{*}{ Yellow Heart } & Heart & Yes & Yes & $.93(.27)$ \\
\hline & & Star & No & No & $.15(.38)$ \\
\hline & \multirow[t]{2}{*}{ Yellow Star } & Heart & Yes & No & $.31(.47)$ \\
\hline & & Star & No & Yes & $.54(.51)$ \\
\hline
\end{tabular}

Table 3. Proportion yes responses for all conditions.
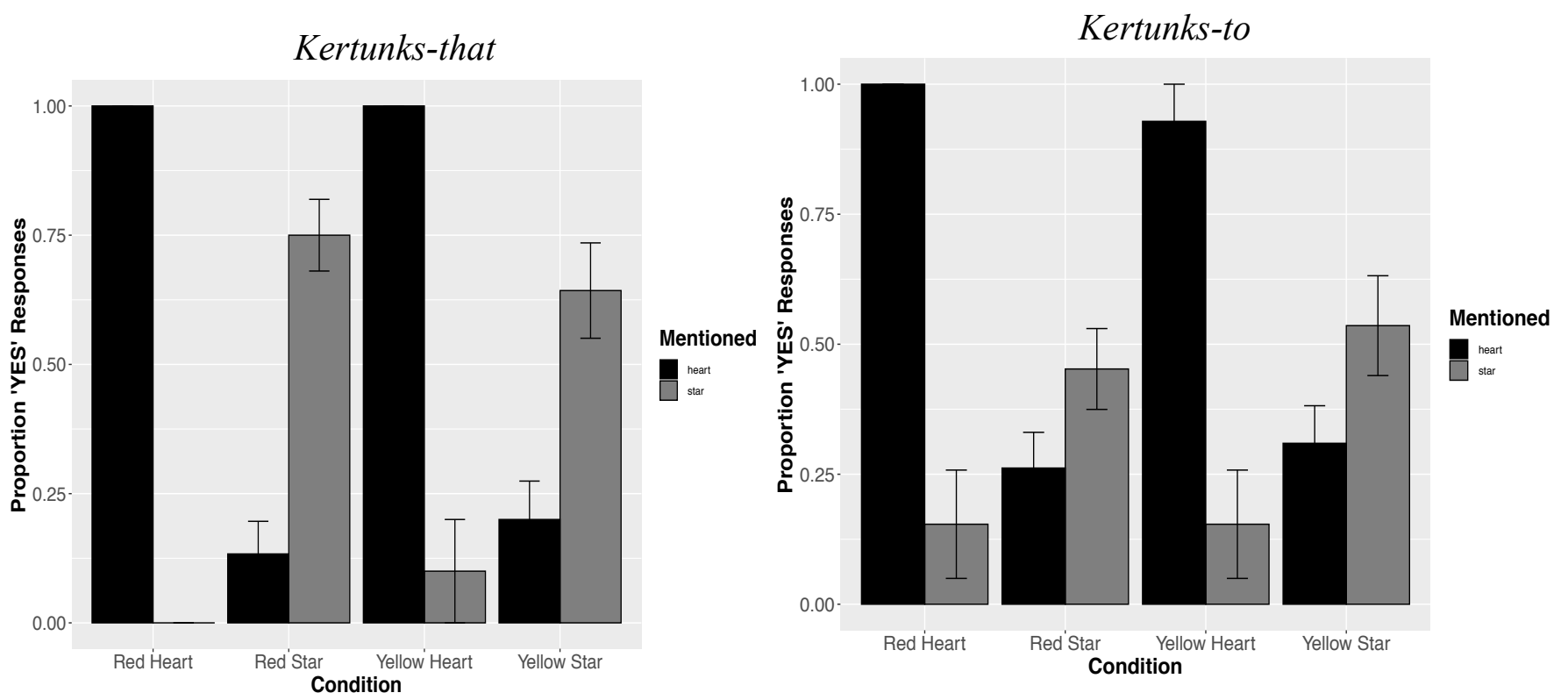

Figure 3. Proportion yes responses for all conditions. Reality responses (shown across both FRAME conditions) are characterized by yes responses when the mentioned shape matches the actual shape.

Children are lured by reality in interpreting sentences with a novel attitude verb: both with a finite and a non-finite complement. Results across both FRAME conditions match the predictions for reality responses. 
STATISTICAL ANALYSIS. The results were analyzed using a generalized linear mixed effects model. These models are well suited for analyzing categorical data (Baayen, 2007; Jaeger, 2008). The reported models have random intercepts. These models predict the probability of a specific response (a correct answer) across different conditions (see Agresti, 2002; Jaeger, 2008). In the first model was a mixed-effect logit model with yes responses as the dependent measure, with FRAME, MENTIONED, and CONDITION as fixed effects, and subject as a random effect. In this model, there is no three-way interaction of FRAME, MENTIONED, and CONDITION $\left[\mathrm{X}_{(1)}^{2}=1.71\right.$, $p=0.633$, showing no statistically significant difference in patterns of responses based on syntactic frame. In this model there is, however, a significant two-way interaction between MENTIONED and CONDITION $\left[\mathrm{X}_{(1)}^{2}=25.90, p<0.001\right]$, showing that although children are not influenced by FRAME, they are sensitive to the match between mentioned and actual shape, showing different response patterns across conditions based on mentioned shape. A second mixed-effect logit model with yes responses as the dependent measure was run, this time excluding FRAME and including only MENTIONED and CONDITION as fixed effects, and subject as a random effect. This model also indicates a significant two-way interaction between MENTIONED and CONDITION $\left[\mathrm{X}_{(1)}^{2}=62.26, p<0.001\right]$. In order to further explore this interaction, we ran four pairwise comparisons over each CONDITION/MENTIONED pair, which reveal a reality-based pattern in children's responses. In the heart conditions, children are significantly more likely to say yes to a mentioned heart and no to a mentioned star. In the star conditions, children are significantly more likely to say yes to star and no to heart. Estimated marginal means and p-values for each condition are reported in Table 4.

\begin{tabular}{llll}
\hline Condition & \multicolumn{2}{l}{ Probability yes response $(\mathrm{SE})$} & p-value \\
\hline & Mentioned Heart & Mentioned Star & \\
\hline Red Heart & $0.93(0.04)^{1}$ & $0.14(0.06)$ & $<.0001$ \\
\hline Red Star & $0.18(0.05)$ & $0.60(0.07)$ & $<.0001$ \\
\hline Yellow Heart & $0.97(0.03)^{2}$ & $0.11(0.06)$ & $<.0001$ \\
\hline Yellow Star & $0.23(0.06)$ & $0.59(0.08)$ & 0.0001 \\
\hline
\end{tabular}

Table 4. Pairwise comparisons of probability yes responses across conditions. In all conditions, children differ significantly in proportion yes responses across mentioned hearts and mentioned stars. In both heart conditions, children are significantly more likely to give yes responses to mentioned hearts than to mentioned stars. In star conditions, we see the opposite patternchildren are more likely to give no responses to mentioned hearts than to mentioned stars.

The statistical models confirm the conclusions: children are giving reality responses in both frame conditions. When they see a heart, they assent to sentences mentioning heart and deny sentences mentioning star. When they see a star, they assent to sentences mentioning star and deny sentences mentioning heart. They are not affected by the puppet's desires (to get hearts), or beliefs (based on color); rather by the match between the mentioned shape and reality.

2.8. Summary. In a context that makes salient beliefs, desires, and reality, 4-year-olds are lured by reality in interpreting sentences with a novel attitude verb regardless of whether the verb is presented with a finite or a non-finite complement. This suggests that syntax is not useful to the learner in a case where they have no prior experience with the verb.

\footnotetext{
${ }^{1}$ In the Red Heart mentioned heart condition, one trial was changed from ' 1 ' to ' 0 ' as models of this type require at least one response of each value across each combination of conditions.

2 In the Yellow Heart mentioned heart condition, one trial was also changed from ' 1 ' to ' 0 '.
} 
3. Discussion. The class of attitude verbs presents an ideal test case for the boundaries of syntactic bootstrapping. They express mental states, which are not directly observable to the learner, and the syntactic distributions of different subclasses of attitude verbs are predictive of their semantic properties. Prior work shows that children are sensitive to verb complement when they are interpreting an attitude verb for which they have not yet solidified their semantic representation (Harrigan et al. 2019). This study used the real verb, hope, which can occur with both finite and non-finite complements. This work serves as a starting point for investigating children's sensitivities to syntax in attitude verb learning, because syntactic complement could be manipulated in the experiment without producing ungrammatical sentences. It also confirmed the longheld hypothesis in the literature that syntax may play a role in children's acquisition of words whose meanings are particularly opaque, such as those referring to the invisible contents of people's minds. The studies on hope, however, left some open questions about the nature and the boundaries of syntactic bootstrapping for attitude verbs. Use of a real verb meant that controlling for participants' prior experience with the verb was impossible - there is no way of knowing whether and how much individual children may have heard hope before participation in the study. This made it impossible to tell how much prior experiences with hope might have contributed to participants' ability to encode and utilize the syntax. This study left open the question that the current study aimed to answer-when does the syntax become useful to the learner?

In the current study, finiteness of the syntactic complement of a novel verb, kertunks, was manipulated between subjects in a context that makes salient both the beliefs and desires of a character, as well as the "reality" in the game. This allows for investigation of whether finiteness of a complement leads the learner to different interpretations of sentences with kertunks, and ultimately is informative about how children may be using syntax to hypothesize the meaning of a truly novel attitude verb. This study finds that, unlike with hope, children are not interpreting the sentences significantly differently based on the syntactic complement. In both the finite and the non-finite conditions, children are more likely to be lured by reality than to respond based on either beliefs or desires. This behavior is predicted in the finite condition - children make the same "reality errors" when interpreting think, and also when interpreting the pseudo-novel verb hope. This behavior is unpredicted, however, in the non-finite condition by the hypothesis that children are utilizing syntactic frame. Non-finite complements predict desire verb semantics in English, and children showed sensitivity to this connection in their interpretation of hope with a non-finite complement in Harrigan et al. 2019. This same sensitivity to the connection between non-finiteness of a complement and desire meaning was not observed with a truly novel verb in the current study.

3.1. REMAINING QUESTIONS. The current study explored the robustness of children's ability to use syntax for attitude verb acquisition, ultimately finding that children are less sensitive to syntax with a novel verb, kertunks, than with the real verb hope. This study leaves us with remaining questions about exactly the role of children's prior experiences with hope. What information are children getting from their initial exposures to an attitude verb? This information must be informative enough to put the learner in a position that triggers sensitivity to syntax for further hypothesizing meaning, but not informative enough for children to be adult-like in their semantic representation. Several hypotheses remain about the observed differences between hope and kertunks. Perhaps there is a more significant processing for interpreting sentences with novel verbs, which causes children to default to reality responses in the current study. If this is the case, then simply giving children prior exposure to our novel verb in any format may be enough to ease the processing load and and make utilizing the syntax accessible to them. It is also possible that there 
is something in (at least some of) children's early experiences with hope that cues children in to some basic semantic properties. For example, perhaps hearing sentences in utterances such as in (17) alerts children to its semantic class as a verb referring to mental states.

I kertunk that we're going to the zoo, and my friend kertunks to go, too!

Perhaps once children recognize that a verb is in the broader class of attitude verbs, only then are they able to use the syntax to further refine semantic representation and hypothesize the more specific attitude verb subclass to which it belongs. Finally, it is possible that syntax is enough for children to hypothesize subclass of attitude verb, and that the syntactic exposure provided for children in the context of this experiment has simply not been enough. If this is the case, then simply providing the child with more test questions - perhaps across two sessions-should improve children's sensitivity to syntax. Future work will explore some of thee possibilities, attempting to uncover exactly what it is in children's early experiences with an attitude verb, such as with hope prior to participating in the study reported in Harrigan et al. 2019, that makes syntax available to the learner as a cue for categorizing attitude verbs.

4. Conclusion. The current study compared children's interpretation of sentences with a novel attitude verb in a context that makes salient beliefs, desires, and reality. This study manipulated finite-ness of the complement in order to test whether 4-year-olds are sensitive to syntactic structure when interpreting a completely novel attitude verb. This study does not find significant differences between children's interpretation of the sentences with a finite and non-finite complement, suggesting that the difference reported in Harrigan et al. with hope was at least partially driven by children's prior experiences with hope. This work begins to better understand children's utili-zation of syntax for attitude verb acquisition - although finiteness of the complement is a useful cue to the learner at some points in development, it is not a cue that is available to them with a completely novel verb. This work expands knowledge of how syntax contributes to attitude verb learning, and ultimately deepens our of understanding of the human language system and the learning mechanisms in the child.

\section{References}

Agresti, Alan. 2002. Categorical data analysis, 2nd Edn. New York, NY: Wiley.

Anand, Pranav \& Valentine Hacquard. 2013. Epistemics and attitudes. Semantics and Pragmatics 6. 8:1-59. https://doi.org/10.3765/sp.6.8.

Baayen, R. Harald. 2007. Analyzing linguistic data: A practical introduction to statistics. Cambridge: Cambridge University Press.

Bolinger, Dwight. 1968. Aspects of language. New York, NY: Harcourt, Brace \& World. de Villiers, Jill G. \& Peter A. de Villiers. 2009. Complements enable representation of the contents of false belief: Evolution of a theory. In S. Foster-Cohen (ed.), Language acquisition. 169-195. Palgrave, Macmillan. Hove: Psychology Press.

de Villiers, Jill G. \& Jennie Pyers. 2002. Complements to cognition: a longitudinal study of the relationship between complex syntax and false-belief understanding. Cognitive Development 17.1037-60.

Farkas, Donka. 1985. Intensional descriptions and the Romance subjunctive mood. New York, NY: Garland.

Fisher, Cynthia H., Henry Gleitman \& Lila R. Gleitman. 1991. On the semantic content of subcategorization frames. Cognitive Psychology 23. 331-392. https://doi.org/10.1016/0010-0285(91)90013-E. 
Fisher, Cynthia, Yael Gertner, Rose M. Scott \& Sylvia Yuan. 2009. Syntactic bootstrapping. WIREs: Cognitive Science 1. 143-149. https://doi.org/10.1002/wcs. 17.

Giannakidou, Anastasia. 1997. The landscape of polarity items (Doctoral thesis). University of Groeningen, The Netherlands.

Gleitman, Lila. 1990. The structural sources of verb meanings. Language Acquisition 1(1). 3-55. Hacquard, Valentine \& Jeffrey Lidz. 2018. Children's Attitude Problems: Bootstrapping verb meaning from syntax and pragmatics. Mind and Language 33(3).1-18.

Harrigan, Kaitlyn. 2015. Syntactic bootstrapping and the acquisition of attitude verbs: Think, want and hope. College Park: University of Maryland dissertation.

Harrigan, Kaitlyn, Valentine Hacquard \& Jeffrey Lidz. 2018. Three-year-olds' understanding of desire reports is robust to conflict. Frontiers in Psychology 9. 119.

Harrigan, Kaitlyn, Valentine Hacquard \& Jeffrey Lidz. 2019. Hope for boostrapping. Language 95(4). 642-82. https://doi.org/10.1353/lan.2019.0067.

Hooper, Joan B. 1975. On assertive predicates. In John Kimball (ed.), Syntax and Semantics, Volume 4. 91-124. Leiden: Brill.

Jaeger, T. Florian. 2008. Categorical data analysis: away from ANOVAs (transformation or not) and towards logit mixed models. J. Mem. Lang. 59. 434-446.

Naigles, Letitia. 1990. Children use syntax to learn verb meanings. Journal of Child Language 17(02). 357-374.

Papafragou, Anna, Kimberly Cassidy \& Lila Gleitman. 2007. When we think about thinking: The acquisition of belief verbs. Cognition 105. 125-165. https://doi.org/10.1016/j.cognition.2006.09.008.

Perner, Josef, Manuel Sprung, Petra Zauner \& Hubert Haide. 2003. 'Want that' is understood well before 'say that', 'think that', and false belief: A test of de Villiers's linguistic determinism on German-speaking children. Child Development 74. 179-188.

Portner, Paul. 1992. Situation theory and the semantics of propositional expressions. Amherst: University of Massachussetts dissertation.

Rakoczy, Hannes, Felix Warneken \& Michael Tomasello. 2007. 'This way!', 'No! That way!' -3-year-olds know that two people can have mutually incompatible desires. Cognitive Development 22. 47-68. https://doi.org/10.1016/j.cogdev.2006.08.002.

Searle, John \& Daniel Vanderveken. 1985. Foundations of illocutionary logic. Cambridge, UK: Cambridge University Press.

Villalta, Elisabeth. 2000. Spanish subjunctive clauses require ordered alternatives. Semantics and Linguistic Theory (SALT) 10. 239-256. https://doi.org/10.3765/salt.v10i0.3123.

Villalta, Elizabeth. 2008. Mood and gradability: An investigation of the subjunctive mood in Spanish. Linguistics and Philosophy 31. 467-522. https://doi.org/10.1007/s10988-008-9046-x.

Wellman, Henry \& Jacqueline Wooley. 1990. From simple desires to ordinary beliefs: The early development of everyday psychology. Cognition 35(3). 245-275. https://doi.org/10.1016/0010-0277(90)90024-E.

Wellman, Henry, David Cross \& Julanne Watson. 2001. Meta-analysis of theory-of-mind development: The truth about false belief. Child Development 72. 655-684.

Yuan, Sylvia \& Cynthia Fisher. 2009. 'Really? She blicked the baby?' Two-year-olds learn combinatorial facts about verbs by listening. Psychological Science 20(5). 619-626. https://doi.org/10.1111/j.1467-9280.2009.02341.x. 